\title{
Articles
}

\section{Hand in Hand: A Comparison of Gestures Accompanying Japanese Native Speaker and JSL Learner Refusals}

\author{
Nicholas O. Jungheim \\ Waseda University
}

The purpose of this study is to describe how native speakers of Japanese and Japanese as a second language learners use gestures as an integral part of Japanese refusals. Participants were 10 native speakers and 33 Japanese as a second language learners who performed a series of role plays that included refusals. This study focused on refusals of an offer and refusals of an invitation. Although learners tended to use manual gestures with refusals of an offer and head movements with refusals of an invitation as did native speakers, there were noticeable differences in the actual performance of these gestures. Implications are that in spite of experience living in the Japanese culture, learners could possibly benefit from additional instruction dealing with gestures as an integral part of Japanese refusals.

本研究は、日本人母語話者と第 2 言語としての日本語学習者が、日本語の断り表現にお ける主要な表現手段としてのジェスチャーをどのように用いているかを明らかにしようと したものである。被験者は 10 人の母語話者と 33 人の日本語学習者で、断りを含む一連 のロールプレイを行った。特に焦点を当てたのは、何かの申し出に対する断りと招待に対 する断りである。学習者は母語話者と同様に、申し出に対する断りには手の動きで、招待 に対しては頭の動きでそれを示す傾向にあったが、実際のこれらのジェスチャーには顕著 な違いが見られた。この結果は、日本の文化に触れる経駼がすべてなのではなく、日本語 の断り表現としてのジェスチャーを大切な要素として学習者に指導することによっても学 習者がそれを学べる可能性があることを示唆している。

JALT Journal, Vol. 26, No. 2, November, 2004 
$\mathrm{L}$ anguage learners in a second language context (i.e. living in the second language culture) can be judged to have lower proficiency in that language if their nonverbal behavior differs enough from the native speaker norm (Neu, 1990). Attempts have been made to develop testing instruments that enable the evaluation of learners' nonverbal behavior separately from their linguistic behavior (Jungheim, 1995, 2001). However, in the field of pragmatics, few researchers have investigated what nonverbal behaviors accompany speech acts performed by language learners, with the notable exception of Gass and Houck (1999). Unfortunately, although they looked at some behaviors that accompany refusals of Japanese learners of English, they did not consider the possibility of cross-linguistic influence in their description of one participant's "hand wave" (pp. 125-128), a behavior that is commonly seen in Japan and is also listed in the Morris (1999) gesture dictionary as the "Hand Fan" (p. 110) indicating negation.

In intercultural interactions where the interlocutors do not necessarily share the same interpretations and usage of nonverbal behaviors, such as gestures that accompany speech, these behaviors can still influence the speakers. In the following example from Fujimoto, Jungheim, Ryan, and Tatsuki (2002), Akiko, a Japanese woman, is talking to Stephanie, a native speaker of English who wants to leave their volunteer group. Brackets indicate the gesture phrase with descriptions of the nonverbal behavior in parentheses.

A: Yeah yeah I will try to ask our members that whether we can uh postpone the deadline from the end of July to the end of August so that

S: [(Stephanie sits up and leans (forward) as if she wants to speak)]

A: [I understand you are busy but] uh can you? (gestures with both hands, palms forward, for Stephanie to "wait") (p. 925)

Stephanie's change in posture interrupts Akiko and in effect amounts to her taking a turn in the conversation. This elicits a response from Akiko that is essentially a request to wait and let her continue speaking. Although the language itself is not a request, the pragmatic synchrony rule (McNeill, 1992) tells us that co-occurring speech and gesture have the same pragmatic function. The gesture actually disambiguates the illocutionary force of the utterance. Speech and gesture are inseparable, and their combination is essential for successful communication here. 
As can be seen in the above example, gestures can play an essential part in defining what speech act is being performed. Since understanding and performing refusals appropriately in a second language can be crucial especially for a low-proficiency learner who may not yet have good control over the target language, it is important that we understand exactly what refusal behaviors are. The focus of this study is an examination of what nonverbal behaviors are associated with Japanese refusals and comparison of how native speakers and second language learners perform them. First, however, it will be necessary to take a look at the literature to see what gestures in general may be related to refusals, regardless of language.

\section{Defining Behaviors}

Broadly speaking, any gesture related to the concept of negation is a candidate for use as a refusal gesture. Before we can discuss possible gestures found in gesture dictionaries and other sources, it is necessary to define gesture categories and situate refusal gestures among them.

\section{Gesture Categories}

Revisiting previously covered ground (Ekman \& Friesen, 1969), Ekman (1999) updates his work on body movements and facial expressions and explains his four categories of gestures: emblems, illustrators, manipulators, and regulators. Of most interest in our discussion of refusals are emblems, "...movements (that) have a set of precise meanings which are understood by all members of a culture or subculture" (p. 45). An emblem can occur with the word it represents, replace it, be a separate comment about it, or be the actual reply. It can also be iconic in the sense that it resembles the thing it represents. Emblems are also usually performed directly in front of the speaker in the area between the head and the waist. This has been referred to as the center of the gesture space (McNeill, 1992).

The term "emblem" was originally adopted by Efron (1941) in his study of gestures used by Eastern Jews and Southern Italians in New York City. He also introduced a concept of hybrid gestures. These he described as gestures that combined elements of gestures from a person's traditional culture with elements of American gestures. This type of gesturer is compared to someone who is bilingual and uses elements of one language when speaking in another. This should not be confused 
with code-switching since it is not a matter of switching back and forth between first and second language gestures, but rather using gestures that combine elements of both systems. For the language learner this resembles the concept of an interlanguage of gestures (Jungheim, 2000), usage that is somewhere in between the first language and the target language.

McNeill's $(1985,1992)$ work on the use of gestures in narratives is based on the concept that gesture and speech are part of the same cognitive process and not separate systems. He divided gestures into representational gestures, which include iconic and metaphorical gestures, deictic or pointing gestures, and beats that provide emphasis. In his discussion of emblems (McNeill, 1992), he cites Kendon's (1981) work that suggests emblems are themselves speech acts but are limited in their functions. McNeill notes that the use of the emblem without speech is based on a "belief in word magic" (p. 65). A speaker must bear a stronger responsibility for his actual words so that the use of the gesture alone alleviates some of this responsibility.

\section{Refusal Gestures}

In general, refusal gestures can be found under the category of negation. In his very early work on gestures, de Jorio (1832/2000) provides detailed descriptions, albeit without illustrations, of some emblems used in Naples. Some of the more familiar gestures of negation that he describes include "head held vertical, turning it alternately from right to left, the neck remaining straight" (p. 290), "open hand raised and oscillated from right to left" (p. 292), and "hands lifted naturally towards the shoulders, with the palms opposed to whatever is denied or rejected" (p. 294). Under the subheading of refusal, he notes that any gesture that is used to express negation can also mean the refusal of something offered and adds another gesture, "hand held with palm up, a little curved, oscillating between the two interlocutors" (p. 343). Thus, we can see various familiar gestures from the head shake to gestures that share an orientation with the common gesture for "stop."

Illustrations in the back of Efron (1941) include some of the above emblems. Two-hand vertical gesticulation in Figure 12 resembles de Jorio's (1832/2000) one-handed right to left oscillating gesture. No. 1 in Figure 48 is described as rejection and resembles de Jorio's refusal gesture above. These similarities testify to the widespread similarity of these refusal gestures across cultures. 
The Japanese version of Body Talk: A World Guide to Gestures (Morris, 1999), as cited above, contains the gesture Morris calls the "Hand Fan" (p. 110) meaning "no." This is apparently unique to Japan. The other refusal gesture in this work is his "Hand Wag" (p. 135), considered to be in widespread use and resembling the right-left oscillating gestures cited above with spread fingers and palm toward the interlocutor. It is interesting that the description of the background of this gesture includes the expression "Iie kekkou!" (p. 135), the basic and possibly generic Japanese refusal, which roughly translates as "No, thank you." Many years ago my Japanese language teacher taught my class that this expression could be used in almost any refusal situation. This was probably her way to simplify this speech act for the raw beginners in the class, even though refusing in Japanese is not really such a simple matter. In any event, considering the number of gestures in this dictionary, it is curious that only two are related to negation, and one of these is unique to a particular non-Western culture. On the other hand, another Japanese collection of 50 gestures (Kanayama, 1983) compiled to compare the usage of gestures in 20 countries does not include this idiosyncratic Japanese hand fan gesture.

Finally, in a dictionary of signs that includes a greater variety of Japanese gestures (Egawa, Aoki, \& Hirata, 1985), we can find "kubi yoko furi" (p. 11) or the head shake indicating disagreement or negation and "te no hira tate" resembling the palm-forward stop gesture meaning "wait." The latter is a one-hand variation of the Akiko example (Fujimoto et al., 2002) cited at the beginning of this paper.

\section{Learner-Related Studies}

A number of learner-related studies have investigated the ability of learners to encode and decode emblems (Jungheim, 1995; Kumin \& Lazar, 1974; Mohan \& Helmer, 1988). In this section I will look briefly at what emblems of negation were included in each.

Kumin and Lazar (1974) investigated the ability of 3- and 4-year-olds to encode and decode a collection of 30 emblems including only those that could be identified by all members of a baseline group of college students. They found that age affected the ability to encode and decode, suggesting a learning effect for these children. Although there are no descriptions of the actual gestures used in their videotape, it can be inferred from their list that "no" is probably a headshake and "stop" is probably the standard palm forward gesture resembling matte in Egawa 
et al. (1985). Nothing directly interpretable as a refusal is included in the 30-emblem list.

Mohan and Helmer (1988) compared native speaker and second language learner preschoolers' ability to interpret a 36-gesture repertoire of emblems and illustrators, which literally illustrate speech. They also found that English as a second language (ESL) children understood less than native speakers, and they also found an effect for age and cultural familiarity. Again, there are no concrete descriptions, but judging from their list of gestures, there are "no" for a headshake, "stop" for the palm forward emblem, and once again, no gesture items directly designated as refusal language.

The purpose of Jungheim's study (1995) was to describe the development of tests of nonverbal ability for Japanese English as a foreign language (EFL) learners. It describes the development of a gesture test for Japanese adults using classical item analysis. In the first stage, a list of 54 gestures was compiled from previous research (Jungheim, 1991; Kumin \& Lazar, 1974; Mohan \& Helmer, 1988). This list was shown to three North American native speakers of English who were asked to cross out the gestures they felt would not be useful for language learners, to write simple descriptions of the remaining gestures, and to perform them for a Japanese nonnative speaker of English who wrote down the meaning. This resulted in an initial list of 38 emblems that were reproduced in a videotape and shown to a group of English native speakers and Japanese nonnative speakers of English, who wrote what they thought each gesture meant. A Japanese English teacher and a native speaker English teacher rated the resulting answers. Item analysis of these results eliminated eight gestures, and the rest were arranged in a new video with a multiple-choice answer sheet for the final form. Since the original list was based on previous research, it is not surprising that it included the headshake for "no," the palm forward gesture for "stop," and no other emblem directly related to refusal language.

In the case of "no," all of the native speakers and almost all of the Japanese English speakers interpreted it correctly in the open-ended task. Interestingly, only 77 percent of the 56 Japanese EFL learners answered this correctly. For "stop," all of the native speakers but only 85 percent of the Japanese English speakers answered correctly in the open-ended task. The Japanese meaning of matte (Egawa et al., 1985) or wait may have interfered with their interpretations. On the multiple-choice gesture test 89 percent of the participants answered correctly.

In Kumin and Lazar (1974), 3-year-olds did not do as well as 4-yearolds for either "no" or "stop." As for Mohan and Helmer (1988), native 
English speaker 5-year-olds ranked much higher than ESL participants or 4-year-olds in their ability to decode "stop," although overall native speakers and learners performed about equally as well for "no."

In summary, the above studies provide some evidence that even such apparently transparent emblems as the headshake and the palm-forward "stop" are learned in English. This is especially evident from the studies that include language learners (Jungheim, 1995; Mohan \& Helmer, 1988). Poorer ability to identify "stop" by Japanese EFL learners may be a case of cross-linguistic influence (i.e., possible pragmatic transfer of the semantic form from Japanese) (Beebe, Takahashi, \& Uliss-Weltz, 1990; Kasper, 1992).

\section{Research Questions}

The purpose of this study, therefore, is to investigate what behaviors are associated with Japanese refusals and examine how native speakers and second language learners perform these in the same situations. In an effort to better understand this issue, this study asks the following questions.

1. To what extent are nonverbal behaviors associated with native speaker and nonnative speaker refusals in Japanese?

2. To what extent do differences in the performance of nonverbal behaviors between native and nonnative speakers of Japanese suggest an interlanguage of refusals?

\section{Methods}

Participants

The participants were 10 native speakers of Japanese ( 8 female and 2 male) and 33 North American English-speaking learners of Japanese (17 female and 16 male). The native speakers were teacher trainees; the learners came from a variety of backgrounds including undergraduate and graduate students and nonstudents.

\section{Procedures}

Participants were divided into three equal groups based on their Japanese as a second language (JSL) proficiency measured using a cloze test (Yamashita, 1994) as a holistic measure of their general linguistic 
proficiency in Japanese. Participants performed eight role play situations (Yamashita, 1996) controlled for power, degree of imposition, and distance. Each situation required the performance of a request, a refusal, and an apology. Although role plays have been used in very few studies in pragmatics, their results exhibit qualities similar to authentic conversation, making them an excellent tool for studying speech acts (Kasper \& Dahl, 1991). The resulting 348 refusals were captured into mpeg video files and coded for the type of gesture or head movement, and the information was entered into a spreadsheet for analysis.

Refusal behavior was analyzed in relation to two eliciting speech acts, refusal of an offer and refusal of an invitation, after an initial review of the 348 clips revealed these speech acts to be the ones that elicited refusals with gestures by most participants. This resulted in a total of 86 refusals for analysis divided among the three groups. In the first situation, the participant plays the part of a customer who refuses the offer of a drink while waiting at a car garage. In the second situation, the participant is a customer who refuses an invitation to an anniversary sale at a gift shop. Coding of the gestures based on previous research and gesture dictionaries resulted in three specific categories of manual refusal gestures and three categories of refusal head movements. The frequency of persons who performed a particular gesture was counted rather than the number of gestures, since the behavior may have occurred twice in a given performance.

\section{Results}

In the process of coding the gestures in the video clips, two additional gestures were found that were not included in the gestures of negation and refusals covered in the literature review above. These were kubikashige (Egawa et al., 1985) or the head tilt, signifying deliberation or misgiving; and the waist bow described in Morris (1999) as being widespread in Asia and used as a sign of respect.

To simplify the discussion, gestures will be referred to using names adopted from the literature. Thus, the hand wave (Gass \& Houck, 1999) is referred to as the Fan (Morris, 1999), the palm-forward wait or stop gesture as the Stop, the one- or two-handed palm-forward left-right oscillating gesture as the Wag (Morris, 1999), the waist bow as the Bow, the headshake as the Shake, and kubikashige (Egawa et al., 1985) or head tilted to the side as the Tilt. Manual gestures can be distinguished by the orientation of the palm of the hand, the kind of motion, the size of the 
motion, and where the gesture is performed in the gesture space. Head movements can be distinguished by the direction of the movement. The Fan is performed high in the central gesture space near the face with the palm facing to the left or right depending on which hand is used. The Stop is performed low in the gesture space with the fingers together, often toward the thing being refused. The Wag is usually performed in the center of the central gesture space with the fingers spread.

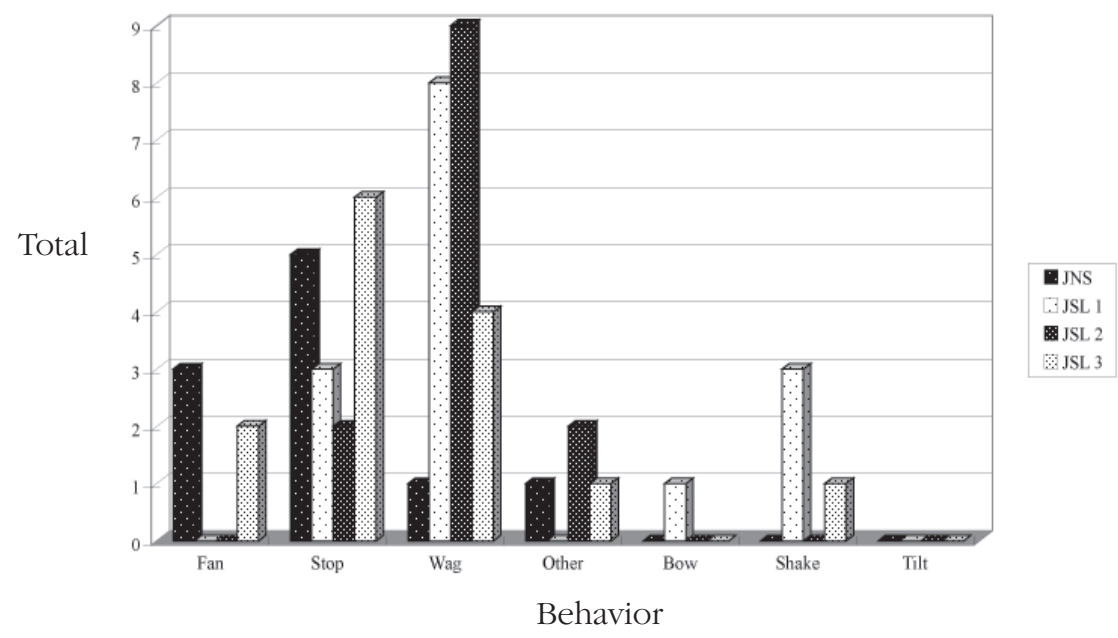

Figure 1. Refusals of an Offer

Figure 1 shows the number of participants in each group who performed each type of behavior with a refusal of an offer. JSL proficiency levels range from the more advanced JSL1 to the less advanced JSL3. The total number is greater than the total number of participants because there were instances when two behaviors were performed by one participant such as a JSL learner who refused the offer of a drink with both the Wag gesture and the head Shake. Native speakers of Japanese only used manual gestures with refusals of an offer, and bows and head movement were rare. The category "Other" included an example of a native speaker who refused a drink by physically pushing it away and followed by the verbal refusal "kekkou desu," as well as nonrefusal gestures such as deictic gestures in which participants pointed at themselves. Only eight examples of Other gestures could be found in the overall total of 96 gestures, including head movement, accompanying refusals. 
Native speakers almost exclusively used the Fan or Stop to refuse the offer, and the Fan was only used by females. Although JSL learners did use the Fan and Stop, a much larger number of them used the Wag performed in the central gesture space.

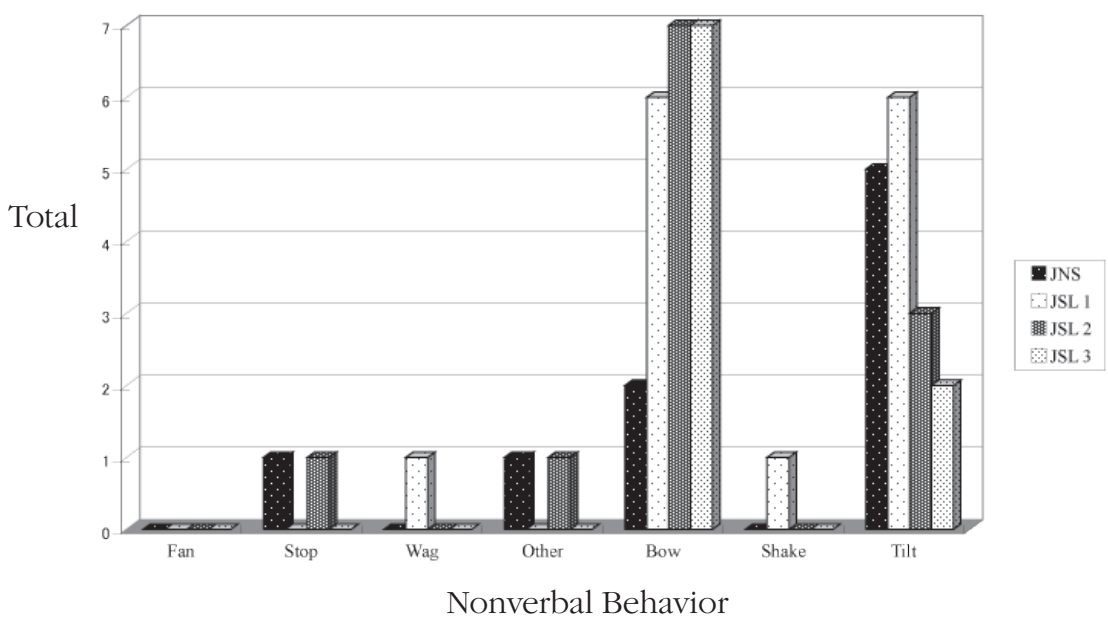

Figure 2. Refusals of an Invitation

Figure 2 shows the number of participants in each group who performed each type of behavior with a verbal refusal of an invitation. Of the 44 gestures performed here, including head movement, only five were manual gestures. Here the overwhelmingly preferred mode of behavior is head movement. Although native speakers of Japanese did not bow very much, bowing was used by a large proportion of JSL learners at each level. As with refusals of an offer, none of the Japanese native speakers used a head Shake, and there was only one example of a JSL learner doing so. The head Tilt was the other preferred behavior, although it was used fewer times by the more advanced JSL learners.

The following discussion will provide specific examples of the nonverbal behaviors used by Japanese native speakers and JSL learners and explore possible reasons for differences between these two groups with implications for an interlanguage of gestures. 


\section{Discussion}

This study was an attempt to describe the nonverbal behaviors (i.e., gesture and head movement) used by Japanese native speakers and JSL learners with refusals. The focus of the analysis was narrowed to the refusal of an offer and the refusal of an invitation. There was a basic difference between how refusals were realized in relation to offers and invitations, with manual gestures dominating refusals of offers and head movement dominating refusals of invitations, regardless of whether the speaker was a native speaker or a learner. Differences between native speaker and learner use of these behaviors in relation to refusals of the same speech acts provide evidence for the existence of an interlanguage of gestures.

\section{Refusing an Offer}

As explained in the above Results section, native speakers of Japanese mainly preferred two types of manual gestures when performing refusals of an offer. These were the Fan and the Stop. Figure 3 illustrates two examples of these with brackets around the gesture phrase and a literal translation of the refusal in English.

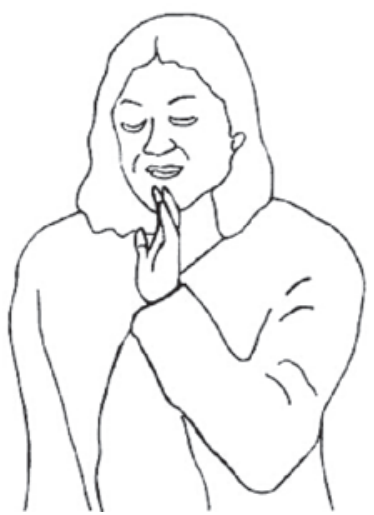

A. [Iie iie kekkou desu]. No, thank you.

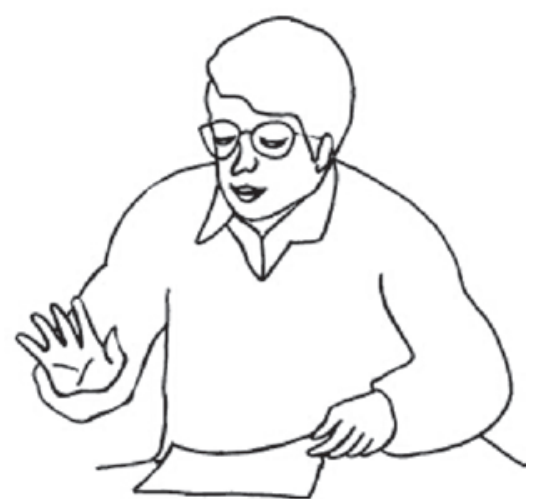

B. [Ano kekkou degozaimasu, ee ima nondekita tokoro desu]. No, thank you. I've already had something to drink.

Figure 3. Japanese native speaker gestures refusing an offer. 
The Fan in Figure 3A is actually composed of four individual waves with a beat-like emphasis punctuating the sentence-final desu. In essence, each of first three waves coincides with an expression of negation, iie, meaning no, and kekkou, a standard refusal expression in Japanese. The final wave has almost a grammatical function in the way it places emphasis on the final verb desu. It is not clear why this participant and another perform this with their left hands, although it is possible that they are left-handed. Those JSL learners who did use this form tended to have little left-to-right motion and therefore lacked this clear coordination of the Fan with the syllables of the refusal. Since only the side of the hand is facing the interlocutor, the size of the gesture appears smaller than the amount of motion would make it appear otherwise.

The Stop in Figure 3B has a slight pushing motion to it. The speaker uses a more polite form of the standard refusal and gives a reason with the gesture phrase covering the whole statement to signify that the reason is also a part of the refusal according to the pragmatic synchrony rule (McNeill, 1992). Unlike the Fan, this is performed lower in the gesture space and toward the object being refused. In both cases the motion is small, and the palm-to-the-side orientation of the Fan gives the gesture a lower profile making it appear smaller in spite of its prominent position near the face. In Japan there is a belief that small, controlled gestures are more highly regarded than exaggerated ones (Tada, 1972, cited in Ishii, 1987). Anecdotal accounts such as the story of a young girl who returns to Japan after a year abroad studying at an American high school and is admonished by her mother for gesturing too much (Jungheim \& Ushimaru, 1990) would seem to support this idea in certain circumstances.

The examples of JSL learners in Figure 4 are variations of the Hand Wag (Morris, 1999), a widely-used gesture that does not appear in the performances of Japanese native speaker refusals of offers. They both use the typical kekkou desu refusal. Their gesturing is notable for the spread of the fingers and the left-right oscillating motion that give the gestures a much larger and energetic appearance than those performed by native speakers in Figure 3. If Tada's (cited in Ishii, 1987) pronouncement about how gesturing is evaluated in Japan is correct, these JSL learners' Japanese proficiency could be less positively evaluated for straying from the Japanese norm, even if their refusals are communicated perfectly well orally. 


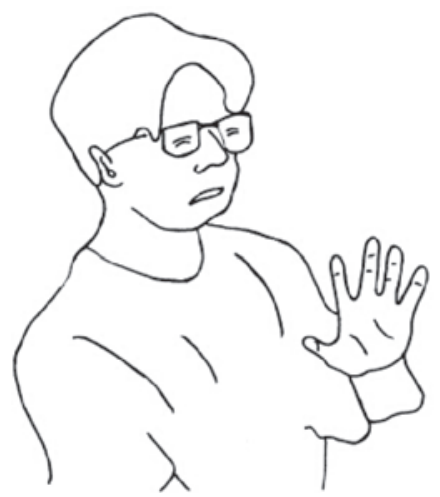

A: [Kekkou desu]. No, thank you.

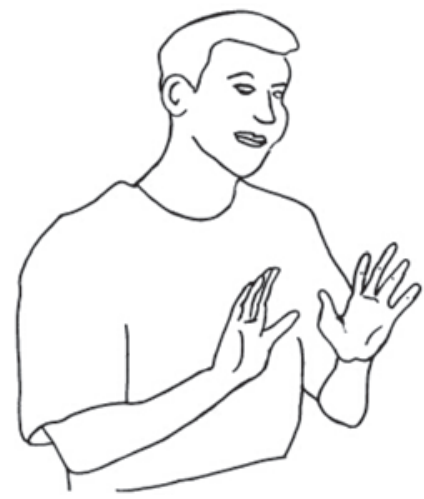

B: [Iranai. Kekkou desu]. I don't need any, thank you.

Figure 4. JSL learner gestures refusing an offer.

\section{Head Movement with Refusals}

As illustrated above in Figure 2, head movement was the dominant form of nonverbal behavior accompanying refusals of an invitation. All groups of JSL learners performed the Bow far more than the group of native speakers. Native speakers appear to prefer the head Tilt, which may indicate doubt or misgiving in Japanese (Egawa et al., 1985). Since the Bow and Tilt are not directly associated with negation or refusals as is the Shake, which was performed only once to refuse an invitation, it is necessary to look at their role in relation to this speech act.

Although Yamashita (1996) did not give raters specific guidelines concerning nonverbal behavior to rate the role play performances from which these refusal examples come, they were instructed to consider these using their "intuition" (p. 61) when rating. The native speaker in Figure 5 refuses the invitation by giving a reason followed by an apology. This is an example of how the apology can be a so-called tail-act in the Japanese refusal (Yamashita, 1996). This means that the apology appears at the end of the refusal formula, unlike English in which the equivalent I'm sorry serves as a head-act, appearing at the beginning of the refusal formula. Following the English convention would result in a lower rating for the speech act in the Yamashita (1996) study. This negative transfer or cross-linguistic influence also appears to trigger 


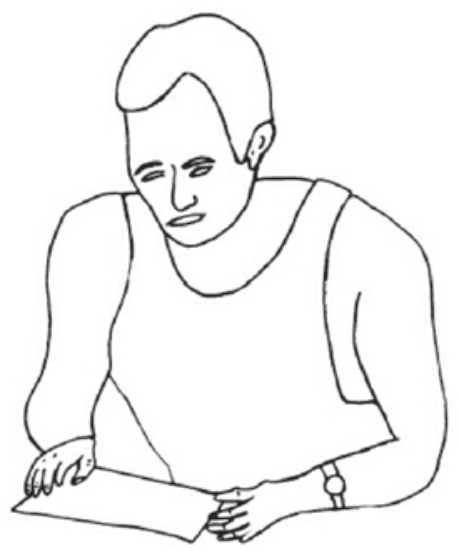

JSL: [Hai, yoroshii desu]. Kekkou desu.

Yes, that will be fine. No, thank you.

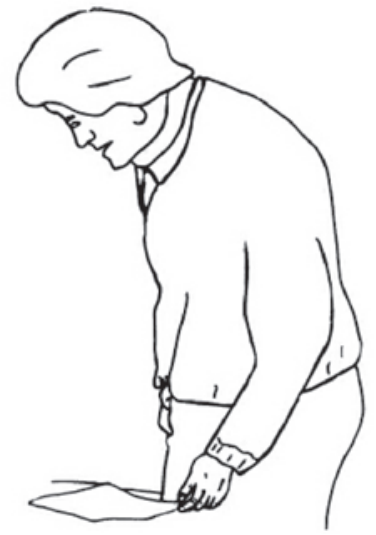

NS: Kore ijou kautsumori gozaimasen no de. [Sumimasen ga].

I don't plan to buy anything else. I'm sorry.

Figure 5. JSL learner and native speaker bowing with refusals.

bowing in the learners, which could make the nonstandard apologyheaded refusal formula even more noticeable to the Japanese raters. This combination of an inappropriate semantic formula with an appropriate Japanese behavior could be considered an example of an interlanguage gesture. The bowing gesture is the appropriate behavior for the apology speech act but, since the refusal formula followed by the learner resembles the English one, it is inappropriate by Japanese norms, making the gesture itself inappropriate. It may be developmental not only in this sense, but also in the sense that it is overused by learners who have not acquired the appropriate refusal formula and are still influenced by their first language, English.

The JSL example of a learner's bow is an example of a refusal of an offer, rather than a refusal of an invitation, but it does illustrate well how appropriate behavior can be found in an inappropriate realization of a speech act. Once again, the formula itself is an inappropriate head-act and followed by the standard refusal expression. However, in this case, even though the head-act expression is completely wrong, its politeness triggers the Bow, an Asian sign of respect or politeness (Morris, 1999). 
Again, the bow only serves to emphasize the inappropriateness of this interlanguage behavior.

In other JSL learner examples of bowing with the refusal of an invitation, bowing accompanies other expressions such as doumo arigatou (thank you) giving an overall impression that learners' interlanguage of gestures also has an element of overcompensation by being too polite and adding the Bow to other expressions that do not appear in native speaker refusals of invitations.

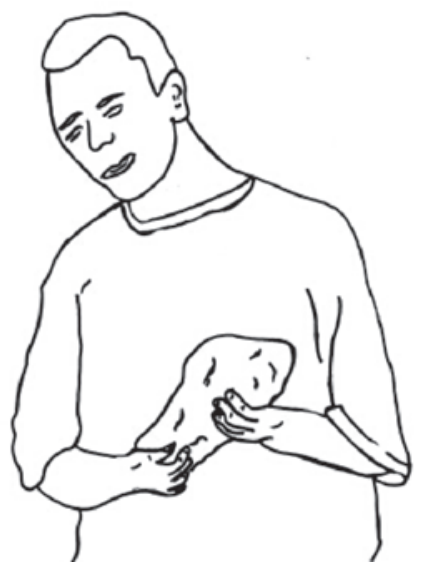

JSL: Watashi no tomodachi no tanjoubi desu. [Zannen deshita ne].

It's my friend's birthday. It's too bad.

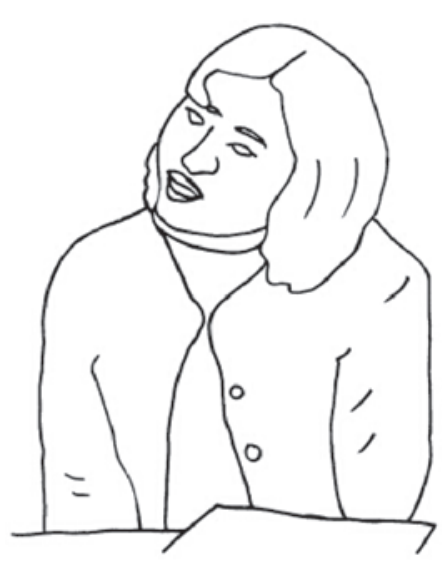

NS: [Doyoubi wa chotto shigotol ga arunde. I'm afraid I'm a little busy on Saturday.

\section{Figure 6. JSL learner and native speaker lateral head shakes with refusals.}

The examples in Figure 6 illustrate how the head Tilt is used to accompany the refusal of an invitation. The gesture phrase for the native speaker covers the reason for the refusal and the expression chotto adding the nuance of deliberation or doubt (Egawa et al., 1985). The expression itself has a wide variety of meanings ranging from "a little" to "somewhat" and is used as an expression to get someone's attention. Here the expression is a hedge (Yamashita, 1996) so that we can also 
interpret the Tilt as a hedging gesture by applying the pragmatic synchrony rule (McNeill, 1992). Three of the native speakers who used the Tilt accompanied it with chotto. The JSL example of the Tilt is performed with the apology zannen deshita or "it's too bad." One of the more common usages of the Tilt by JSL learners is at the beginning of the refusal of the invitation with a reason, just as the native speaker in Figure 6 does, without the expression chotto indicating they may be transferring the hedging Tilt from English, but have not acquired the formula that includes the Japanese hedging expression.

In the above examples of refusal-related gestures, we can see that gestures of negation are not the only types of gestures used. The expression of politeness can be added with the Bow, and refusals can also be ameliorated with a hedge using the head Tilt, especially when it is accompanied by chotto.

\section{Conclusion}

This investigation into what gestures, including head movement, are related to Japanese refusals has shown that refusals of offers by native speakers and JSL learners alike were generally accompanied by manual gestures, in contrast to refusals of invitations, which were mainly accompanied by head movement. Not all behaviors related to refusals were associated with negation. Politeness and hedging behaviors were also found in relation to the Japanese refusals' semantic formula. Differences between Japanese native speaker and JSL learner nonverbal realizations may be a result of cross-lingual influence from the participants' first language, English, suggesting that gesture use may also be an important part of interlanguage pragmatics.

The purpose of this study was explorative and descriptive. No attempt was made to examine whether there were any statistically significant differences among the four groups or their gestures. Gender may also play a part in the results, since eight out of 10 native speakers were women. A larger sample for baseline data could give us more confidence to say what the possible refusal behaviors are. The examples of similar behaviors in similar situations do, however, provide us with some understanding of how gestures are used with two types of Japanese refusals.

The dictionaries and other sources present emblems as a very cutand-dried phenomenon. They have even been referred to as "quotable gestures" (Kendon, 1984). Ekman (1999) speculates that, "It is my im- 
pression that it is easy to learn foreign emblems-easier than it is to learn foreign words-but I have done no research to support that casual observation" (p. 46). If learners are truly having such an easy time acquiring these gestures, we would expect to see more appropriate use among the more proficient participants in this study and those who have lived in Japan for an extended period. The results of this study do not appear to support such a conclusion.

What the results of this study do suggest is that a refusal gesture is not just a simple body movement that can be memorized and performed correctly. Neither traditional drill and practice nor more communicative methods tried in the past seem to improve even the comprehension of other emblematic gestures (Jungheim, 1991). There is an intimate relationship not only between the gesture and refusal expression, but also between the gesture and the overall refusal formula.

One implication of this study is that experiencing refusal gestures in a natural context is not sufficient to acquire their appropriate use. There is no evidence that gesture as a component of Japanese speech acts is actually taught in JSL classrooms to any extent. Participants in this study had a wide range of experience in terms of years of study. In spite of many years of experience, more advanced learners still exhibited refusal behaviors that differed from what may be considered appropriate by native speaker norms. If appropriate gestures are important for learners to be evaluated positively as speakers of Japanese as a second or foreign language, it is essential that methods be explored that will develop their ability to use gestures appropriately as an integral part of speech acts such as refusals.

A series of activities such as those described by Fujimori and Houck (2004) is a good starting point. Consciousness-raising tasks that utilize scenes containing appropriately performed refusal routines taken from movies could also provide a useful introduction to refusal gestures. The viewing of these video scenes could be preceded by role plays requiring refusals and followed up with additional role playing accompanied by peer rating and discussions of students' performances. Keep in mind that refusals are always in response to another speech act. Instruction in speech acts that includes the use of gestures must be carefully designed to distinguish among the various types of eliciting speech acts. Thus, refusals might better be taught in conjunction with other speech acts to ensure that learners develop sensitivity to differences in appropriate refusal gesture responses.

Work in progress (Jungheim, 2002) is an attempt to take a closer look at how Japanese native speakers and JSL learners interpret refusal 
gestures. Preliminary findings suggest that, although native speakers are better than JSL learners at interpreting refusal gestures, their interpretations often include behaviors that differ from the gestures viewed. How are the unconsciously-observed gestures processed to produce such differences? Further examination of learner perceptions and performances of refusals may provide additional hints for the classroom. Gestures are an important aspect of some refusals, and learners would appear more proficient if their behavior more closely approximated that of native speakers of Japanese.

Thanks to Sayoko Yamashita for generously allowing me to use her valuable videos for this project and for working with me in the early stages of this study. This study was partially funded by the Research Institute of Aoyama Gakuin University.

Nicholas O. Jungheim is interested in testing and pragmatics and has designed a number of tests of various aspects of language learners' nonverbal ability.

\section{References}

Beebe, L., Takahashi, T., \& Uliss-Weltz, R. (1990). Pragmatic transfer in ESL refusals. In R. C. Scarcella, E. Anderson, \& S. D. Krashen (Eds.), Developing communicative competence in a second language (pp. 55-73). Rowley, MA: Newbury House.

de Jorio, A. (2000). Gesture in Naples and gesture in classical antiquity (A. Kendon, Trans.). Bloomington, IN: University of Indiana Press. (Original work published 1832).

Efron, D. (1941). Gesture and environment. New York: King's Crown Press.

Egawa, K., Aoki, T., \& Hirata, Y. (1985). Kigo no jiten [A dictionary of signs]. Tokyo: Sanseido.

Ekman, P. (1999). Emotional and conversational nonverbal signals. In L. S. Messing \& R. Campbell (Eds.), Gesture, speech, and sign (pp. 45-55). Oxford: Oxford University Press.

Ekman, P., \& Friesen, W. V. (1969). The repertoire of nonverbal behavior: Categories, origins, usage, and coding. Semiotica, 1, $49-98$.

Fujimori, J., \& Houck, N. (2004). Practical criteria for teaching speech acts. The Language Teacher, 28(5), 3-8. 
Fujimoto, D., Jungheim, N. O., Ryan, S., \& Tatsuki, D. (2002). Pragmatics and intercultural communication compared. In M. Swanson, D. M. Murray, \& K. Lane (Eds.), PAC3 at JALT2001 Conference Proceedings (pp. 923-931). Tokyo: Japan Association for Language Teaching.

Gass, S. M., \& Houck, N. N. (1999). Interlanguage refusals: A cross-cultural study of Japanese-English. Berlin: Mouton de Gruyter.

Ishii, S. (1987). Nonverbal communication in Japan. Tokyo: The Japan Foundation.

Jungheim, N. O. (1991). A study on the classroom acquisition of gesture in Japan. The Journal of Ryutsu Keizai University, 27(1), 61-68.

Jungheim, N. O. (1995). Assessing the unsaid: The development of tests of nonverbal ability. In J. D. Brown \& S. O. Yamashita (Eds.), Language Testing in Japan (pp. 149-165). Tokyo: JALT.

Jungheim, N. O. (2000, September). An interlanguage of gestures in Japanese learners' L2 discourse. Paper presented at the meeting of the Second Language Research Forum, Madison, WI.

Jungheim, N. O. (2001). The unspoken element of communicative competence: Evaluating language learners' nonverbal behavior. In T. Hudson \& J. D. Brown (Eds.), A focus on language test development: Expanding the language proficiency construct across a variety of tests (Technical Report \#21) (pp. 1-34). Honolulu: University of Hawai'i, Second Language Teaching and Curriculum Center.

Jungheim, N. O. (2002). The perception of gestures occurring with Japanese refusals. Paper presented at the First Congress of the International Society for Gesture Studies, The University of Texas at Austin.

Jungheim, N. O., \& Ushimaru, A. (1990). Kaiwa tatsujin e no michi "pafoomansu" ["Performance"-A key to the art of conversation]. Hayakumannin no Eigo [English for Millions], 5 (May), 20-25.

Kanayama, N. (1983). Sekai 20-koku nonbaaburu jiten [A 20-nation nonverbal dictionary]. Tokyo: Kenkyusha.

Kasper, G. (1992). Pragmatic transfer. Second Language Research, 8(3), 203231.

Kasper, G., \& Dahl, M. (1991). Research methods in interlanguage pragmatics (Technical Report \#1). Honolulu: University of Hawai'i, Second Language Teaching and Curriculum Center.

Kendon, A. (1981). Geography of gesture. Semiotica, 37, 129-163.

Kendon, A. (1984). Did gesture have the happiness to escape the curse of the confusion of Babel? In A. Wolfgang (Ed.), Nonverbal behavior: Perspectives, applications, and intercultural insights (pp. 75-114). Lewiston, NY: C. J. Hogrefe.

Kumin, L., \& Lazar, M. (1974). Gestural communication in preschool children. Perceptual and Motor Skills, 38, 708-710. 
McNeill, D. (1985). So you think gestures are nonverbal? Psychological Review, 92, 350-371.

McNeill, D. (1992). Hand and mind. Chicago: University of Chicago Press.

Mohan, B., \& Helmer, S. (1988). Context and second language development: preschoolers' comprehension of gestures. Applied Linguistics, 9(3), 275294.

Morris, D. (1999). Bodii tooku: sekai no miburi jiten [Body talk: A world guide to gestures] (Y. Higashiyama, Trans.). Tokyo: Sanseido.

Neu, J. (1990). Assessing the role of nonverbal communication in the acquisition of communicative competence in L2. In R. C. Scarcella, E. S. Andersen, \& S. D. Krashen (Eds.), Developing communicative competence in a second language (pp. 121-138). New York: Newbury House.

Yamashita, S. (1994). Is reading comprehension performance of learners of Japanese as a second language the same as that of Japanese children?-An analysis using a cloze test. Japanese Language Education around the Globe, 4, 133-146.

Yamashita, S. (1996). Six measures of JSL pragmatics (Technical Report \#14). Honolulu: University of Hawai'i, Second Language Teaching and Curriculum Center.

(Received March 12, 2004; accepted May 8, 2004) 